\title{
Cystatin C-positive Macrophages and Dendritic Cells in the Rat Incisor Pulp
}

\author{
Sumio Nishikawa ${ }^{1}$ \\ ${ }^{1}$ Department of Biology, Tsurumi University School of Dental Medicine, 2-1-3 Tsurumi-ku, Yokohama 230-8501, Japan
}

Received October 4, 2004; accepted December 6, 2004

Localization of cystatin $C$, an endogenous cysteine protease inhibitor, was examined in the dental pulp of rat incisors using immunofluorescence microscopy. Based on double labeling with ED1 and anti-cystatin $C$ antibodies, it was determined that anti cystatin C-labeled cells were macrophages and/or dendritic cells. Furthermore, cells in the incisor pulp were characterized by triple labeling with anti-cystatin C antibodies, ED2 antibodies for resident macrophages and OX6 antibodies for MHC class II antigens. Three cysteine proteases, cathepsin B, L and S, were also examined with immunocytochemistry. The results showed, firstly, that cystatin C single-positive cells were localized in early apical pulp, and that these cells were presumably immature macrophages invading newly formed dental pulp. Secondly, about half of $\mathrm{OX6}^{+}$cells in the middle and incisal pulp were ED2 ${ }^{+}$, indicating that resident macrophages in addition to dendritic cells contribute to antigen surveillance via MHC Class II presentation. Thirdly, cathepsin $S$ was present in cystatin $\mathrm{C}^{+}$cells, and therefore they may be involved in formation of proteolytic environment in whole dental pulp. In conclusion, cystatin C-positive macrophages and possibly dendritic cells may play a role in regulating the proteolytic environment of the dental pulp as well as in immunological surveillance.

Key words: cystatin C, dental pulp, macrophages, dendritic cells, cathepsin S

\section{Introduction}

Dental pulp is composed of sparsely distributed fibroblasts, blood and lymphatic vessels and a nerve supply, with large extracellular spaces. Odontoblasts line the periphery of the pulp, to elaborate dentin matrices $[8,26]$. Immune competent cells, such as macrophages and dendritic cells, have also been reported to be abundant in the dental pulp [9, 14, $16,17]$. It is thought that these cells function in immunological defense [9, 17], clearance of apoptotic fragments [14] and elimination of degenerated odontoblasts from the incisal pulp [16]. In rat tissues, the distribution of MHC Class II antigen and CD68-like antigen, both found in dentritic cells and macrophages, can be determined using OX6 and ED1 antibodies, respectively, while the distribution of an antigen specific for macrophages can be determined using ED2 [4, $5,11]$. In incisor pulp, $\mathrm{ED}^{+}, \mathrm{ED} 2^{+}$, or $\mathrm{OX}^{+}$cells are rare in the early pulp region, where a large pulp space is continu-

Correspondence to: Sumio Nishikawa, Department of Biology, Tsurumi University School of Dental Medicine, 2-1-3 Tsurumi, Tsurumi-ku, Yokohama 230-8501, Japan.

E-mail: nishikawa-s@tsurumi-u.ac.jp ously created. In the middle pulp region, these macrophages or dendritic cells are greater in number and often contain ingested apoptotic nuclei [14]. In the late pulp region where pulp cavity is smaller and the dentin thicker, numerous $\mathrm{ED}^{+}{ }^{+}, \mathrm{ED} 2^{+}$, or $\mathrm{OX}^{+}$cells are present [14].

Cystatin $\mathrm{C}$ is an endogenous cysteine protease inhibitor and is secreted extracellularly to function with cysteine proteases, such as cathepsins, in proteolytic regulation $[3,25]$. While cystatin $\mathrm{C}$ is expressed ubiquitously, macrophages have been shown to secrete it and some populations of dendritic cells are also positive for cystatin $\mathrm{C}[3,6]$. In the dental tissues, the rat incisor enamel organ contains $\mathrm{OX}^{+} \mathrm{ED}^{-}$ dendritic cells that are also cystatin C-positive in the transition and maturation zones [15]. Furthermore, in the earlier zone, that is the secretion zone, cystatin $\mathrm{C}$ single-positive cells appear sparsely distributed, and may be precursors to dendritic cells [15].

In the present study, to know the possible involvement of cysteine proteases and endogenous cysteine protease inhibitor, macrophages and dendritic cells in the incisor pulp were examined by triple labeling with anti-cystatin C, ED2 and OX6. 


\section{Materials and Methods}

Six 5-week male Wistar rats (Jcl Wistar, Clea Japan, Tokyo, Japan) were used for immunofluorescence microscopy and enzyme immunohistochemistry. Institutional guidelines for animal care and the "principles of laboratory animal care" (NIH publication No. 85-23, revised 1985) were followed. The animals were perfused under sodium pentobarbital (Nembutal, Abbott, North Chicago, IL) anesthesia with $4 \%$ paraformaldehyde in $0.1 \mathrm{M}$ phosphate buffered solution (PB), $\mathrm{pH} 7.2$, via the left ventricle at room temperature (RT) for $10 \mathrm{~min}$. They were then immersed in the same fixative at $4^{\circ} \mathrm{C}$ for $2 \mathrm{hr}$ and the maxillae and mandibles were dissected. After being washed with $0.1 \mathrm{M} \mathrm{PB}$, the maxillae and mandibles were demineralized by immersion in 5\% EDTA solution adjusted to $\mathrm{pH} 7.3$ with sodium hydroxide solution, at $4^{\circ} \mathrm{C}$ for $3-4$ weeks. Demineralized incisors were cut transversely into two segments. Both segments were immersed in $25 \%$ sucrose in PB overnight, rapidly frozen, and then cut longitudinally (6-8 $\mu \mathrm{m}$ thick) using a cryotome.

Antibodies used in this study were mouse monoclonal ED1, ED2 and OX6 antibodies (Serotec; Oxford, UK), rabbit polyclonal anti-cystatin $\mathrm{C}$ antibody (Upstate Biotechnology, Lake Placid, NY), and goat polyclonal anticathepsin B (E-19), anti-cathepsin L (C-18), and anti-cathepsin S (M-19) antibodies (Santa Cruz Biotechnology, Santa Cruz, CA). Specificities of ED1, ED2, OX6 and anti-cystatin $\mathrm{C}$ have been described elsewhere $[4,5,11,15,19]$.

For quadruple labeling, cryosections were incubated in $1 \%$ bovine serum albumin in phosphate-buffered saline (BSA-PBS) at room temperature (RT) for $30 \mathrm{~min}$. They were then labeled with ED2 antibody diluted 1:200 (5 $\mu \mathrm{g} /$ $\mathrm{ml}$ ) with 1\% BSA-PBS at RT for $30 \mathrm{~min}$, followed by labeling with biotinylated anti-rabbit and anti-mouse immunoglobulin absorbed to abolish cross-reactivity with rat serum proteins (LINK; DAKO LSAB2 Kit, DAKO, Carpenteria, $\mathrm{CA}$ ) at RT for $10 \mathrm{~min}$. Sections were visualized by labeling with $2 \mu \mathrm{g} / \mathrm{ml}$ Rhodamine Red-X-conjugated streptavidin (Molecular Probes, Eugene, OR) at RT for $10 \mathrm{~min}$. After being washed with PBS and incubated with $1 \%$ BSA-PBS, the sections were labeled with a mixture of OX6 antibody diluted 1:100 $(10 \mu \mathrm{g} / \mathrm{ml})$ and anti-cystatin $\mathrm{C}$ antibody diluted 1:100 $(10 \mu \mathrm{g} / \mathrm{ml})$ at RT for $30 \mathrm{~min}$, followed by labeling with a mixture of Alexa 488-conjugated anti-rabbit IgG diluted 1:100, Alexa 647-conjugated anti-mouse IgG diluted 1:100 and $0.5 \mu \mathrm{g} / \mathrm{ml}$ Hoechst 33342 (Molecular Probes). Preliminary experiments revealed ED2 antibody was not visible using simple indirect immunofluorescence microscopy but was detected by more sensitive biotinstreptavidin-based labeling, when specimens were fixed with paraformaldehyde. Therefore, Alexa 647 fluorescence exhibited only OX6 localization. For control sections, mouse isotype control $\mathrm{IgG}$ (mouse $\mathrm{IgG}_{1}$ negative control, DAKO) or rabbit immunoglobulin fraction (DAKO) was used in place of those primary antibodies described above. For immunoperoxidase labeling, DAKO LSAB2 Kit was used according to the manufacturer's instructions. For goat antibodies, donkey anti-goat IgG conjugated with biotin (Santa Cruz) diluted 1:100 was used in place of the link antibody of the LSAB2 Kit. Fluorescent images were visualized using an Olympus AX80 fluorescence microscope equipped with a CCD camera (Quantix KAF1401E, Photometrics, Tucson, AZ) and using MetaMorph software (Universal Imaging, Downingtown, PA) [12]. In quadruple labeling, four cubes for epifluorescence microscopy were used: U-MNUA (Olympus, Tokyo, Japan) filtered through 360-370 nm for excitation and 420-460 nm for emission, U-MNIBA (Olympus) filtered through $470-490 \mathrm{~nm}$ for excitation and 515-550 $\mathrm{nm}$ for emission, Cy3 (U-M41007a, Chroma, Rockingham, VT) filtered through 530-560 nm for excitation and 575$645 \mathrm{~nm}$ for emission, and Cy5 (U-M41008, Chroma) filtered through $590-650 \mathrm{~nm}$ for excitation and 665-735 $\mathrm{nm}$ for emission. Fluorescent images from Hoechst 33342, Alexa 488, Rhodamine Red-X, and Alexa 647 were recorded separately in an appropriate cube, and combined after coloring artificially using MetaMorph software.

Numerical analyses were performed by using sections labeled triply with anti-cystatin C, ED2 or OX6 antibodies. Micrographs were obtained using $\times 20$ or $\times 40$ objective lens. Numbers of cells positive to each antibody were counted in area of $39,000 \mu \mathrm{m}^{2}$ to $157,000 \mu \mathrm{m}^{2}$. In early, middle or late pulp region, six to seven different areas from at least two rats in each region were used for calculation of mean and standard deviation.

Procedures for conventional electron microscopy have been described elsewhere [13].

\section{Results}

All cystatin C and ED1 labeled cells were co-localized (Fig. 1). Thus, at least in the dental pulp of the incisor, cystatin C-labeled cells were macrophages or dendritic cells, since the localization of ED1 is known to be limited in both types of cells [3, 4]. Cystatin C labeling was localized to the cytoplasm and diffuse in nature, although occasional areas of stronger labeling were visible. ED1 labeling was patchy or granular creating difficulties in distinguishing cell outlines.

The incisor pulp was divided into three areas for comparison: early pulp facing the proliferating and differentiating zones of enamel epithelia, middle pulp facing the secretion and early maturation ameloblasts, and late pulp facing late maturation ameloblasts. In the incisor pulp, ED2 ${ }^{+}$and $\mathrm{OX}^{+}$cells increased from the early to the late pulp region. In the early pulp situated close to the apical bud of enamel organ, cystatin $\mathrm{C}$ labeled ED2- $\mathrm{OX6}^{-}$cells were sparsely distributed $\left(0.72 \pm 0.35\right.$ cells per $10,000 \mu^{2}$; mean \pm SD), with some located adjacent to blood vessels (Figs. 2 and $3 \mathrm{~A})$. They appeared oval in shape and their cytoplasm was strongly labeled with cystatin $\mathrm{C}$. ED2 ${ }^{+}$and $\mathrm{OX}^{+}$cells were scarce in this pulpal region. Conventional electron microscopy revealed several small oval cells with many lysosomal granules and electron-dense nucleoplasm, showing that they 



Fig. 1. Double labeling of early (A-C) and middle (D-F) pulp with ED1 $(\mathbf{A}, \mathbf{D})$ and anti-cystatin $\mathrm{C}(\mathbf{B}, \mathbf{E})$. Figures $\mathbf{C}$ and $\mathbf{F}$ show overlaid images of figures $\mathbf{A}$ and $\mathbf{B}$, and figures $\mathbf{D}$ and $\mathbf{E}$, respectively. Bars $=100 \mu \mathrm{m}$.

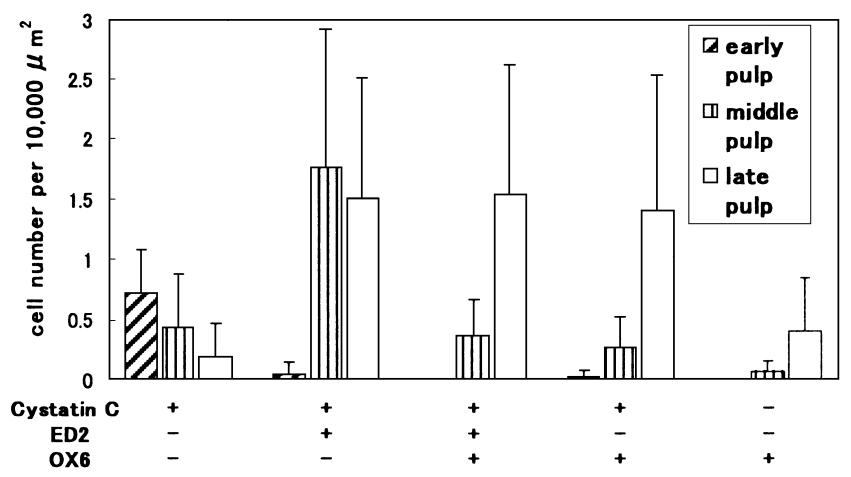

Fig. 2. Density of cystatin C-labeled, $\mathrm{ED}^{+}$, and $\mathrm{OX} 6^{+}$cells in early, middle and late pulp of rat incisors. Single-, double- and triplelabeled cells were counted on triple-labeled sections in an area from $39,000 \mu \mathrm{m}^{2}$ to $157,000 \mu \mathrm{m}^{2}$. Values shown are means and SDs, obtained from 6 to 17 different sections of at least two different rats.


Fig. 3. (A) Triple labeling of early pulp with anti cystatin C (green), ED2 (red) and OX6 (blue). Green-colored round cells staining only with anti cystatin $\mathrm{C}$ antibodies, are distributed sparsely (arrows) and often along blood vessels (arrows in lower right corner). Bar= $150 \mu \mathrm{m}$. (B) An electron micrograph of early pulp. A small oval macrophage is seen. Bar $=2 \mu \mathrm{m}$.

were undifferentiated macrophages (Fig. 3B).

In the middle region of the pulp, cystatin $\mathrm{C}$ labeled ED2- ${ }^{-}$OX6 $^{-}$cells were present, although in reduced numbers, when compared with those in the early pulp. Cystatin $\mathrm{C}$ labeled $\mathrm{ED} 2^{+} \mathrm{OX}^{-}$resident macrophages were present at a density of $1.76 \pm 1.17$ cells per $10,000 \mu \mathrm{m}^{2}$ and cystatin $\mathrm{C}$ labeled ED2 ${ }^{+} \mathrm{OX}^{+}$macrophages were also observed $\left(0.37 \pm 0.30\right.$ cells per $\left.10,000 \mu \mathrm{m}^{2}\right)$. Cystatin $\mathrm{C}$ positive and negative $\mathrm{ED} 2^{-} \mathrm{OX}^{+}$cells were also detected in this region, although the latter were scarce $(0.27 \pm 0.26$ or $0.06 \pm 0.10$, respectively) (Figs. 2, 4). These cell populations may include dendritic cells, since previous reports have revealed $\mathrm{OX}^{+}$dendritic cell-like morphology in immunoelectron microscopy $[10,14,16]$. Macrophages or dendritic cells in this region exhibited cell processes and were occasionally dendritic in shape, unlike the cystatin $\mathrm{C}$ single-labeled cells in the early pulp. In the odontoblast layer, $\mathrm{OX}^{+}$cells adjacent to blood vessels were cystatin $\mathrm{C}^{+} \mathrm{ED} 2^{-}$(not shown). 

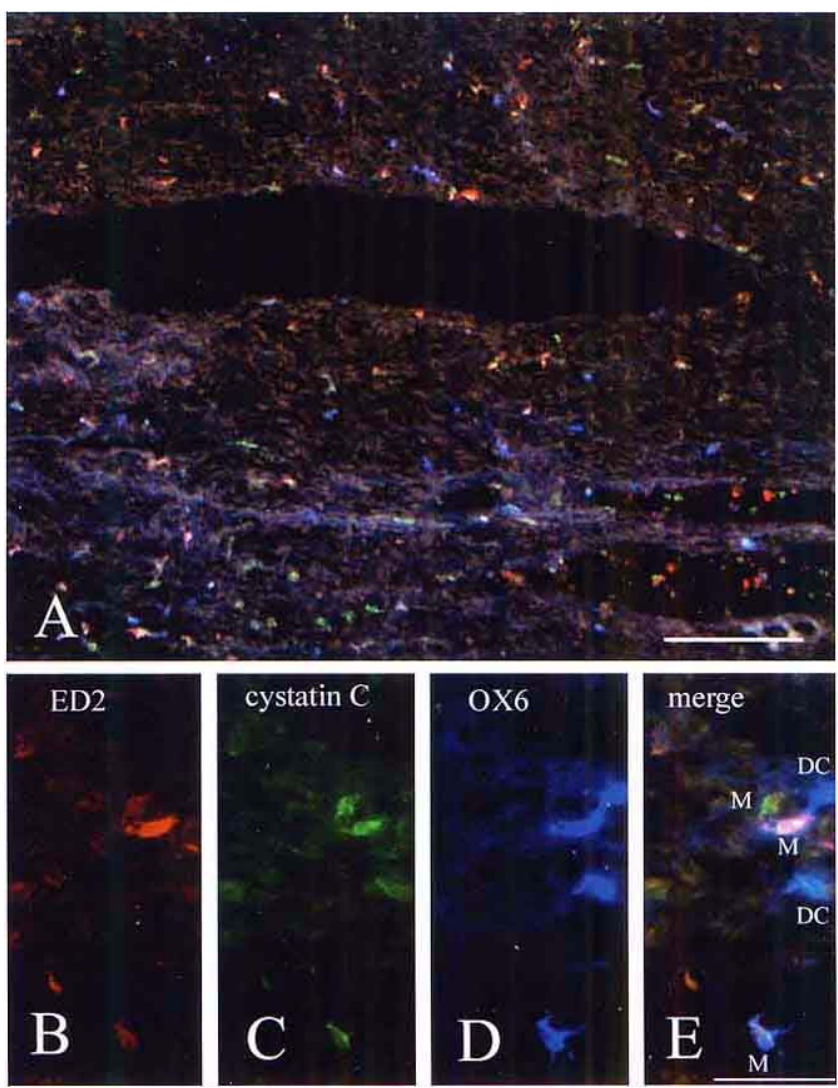

Fig. 4. (A) Triple labeling of middle pulp with anti-cystatin $\mathrm{C}$ (green), ED2 (red) and OX6 (blue). Single-, double- or triplelabeled cells are shown. Most of them are spindle-like or dendritic in shape. Bar $=150 \mu \mathrm{m}$. (B-E) Higher magnification of middle pulp triple-labeled with ED2 (B), anti cystatin C (C), OX6 (D). An overlaid image is also shown $(\mathbf{E})$. One $\mathrm{OX}^{+}{ }^{+} \mathrm{ED}^{-}$cell exhibits weaker anti-cystatin $\mathrm{C}$ reactivity (lower DC in $\mathbf{E}$ ), but the other does not (upper DC in E). ED2 ${ }^{+}$macrophages (M) exhibit stronger anti-cystatin $\mathrm{C}$ reactivity and two of them are $\mathrm{OX}^{+}$(middle and lower Ms in $\mathbf{E}$ ). Bar $=50 \mu \mathrm{m}$.

The cystatin $\mathrm{C}$ labeling pattern differed between $\mathrm{ED} 2^{+}$ resident macrophages and $\mathrm{ED}^{-}{ }^{-} \mathrm{OX}^{+}$cells: the former showed strong broad cytoplasmic labeling, while the latter showed only small limited discrete areas of labeling and occasionally lacked cystatin C labeling (Fig. 4B-E). In the middle to late pulp region, apoptotic nuclear fragments were often observed [14]. These nuclear fragments, viewed using Hoechst 33342, were incorporated into both ED2 ${ }^{+}$ resident macrophages and $\mathrm{ED}^{-}{ }^{-} \mathrm{OX}^{+}$cells.

In the late pulp, cystatin $\mathrm{C}$ labeled ED2- $\mathrm{OX}^{-}$cells were scarce $(0.19 \pm 0.28)$, and cystatin $\mathrm{C}$ labeled $\mathrm{ED}^{+}{ }^{+} \mathrm{OX}^{+}$ macrophages, cystatin $\mathrm{C}$ labeled ED2 ${ }^{-} \mathrm{OX}^{+}$cells and ED2 ${ }^{-}$ $\mathrm{OX}^{+}$cells lacking cystatin $\mathrm{C}$ labeling were seen more frequently $(1.54 \pm 1.09,1.40 \pm 1.13$ and $0.39 \pm 0.44$, respectively) (Figs. 2 and 5).

Since cystatin $\mathrm{C}$ is a secretory protein and an endogenous cysteine protease inhibitor, immunohistochemistry with cathepsin $\mathrm{B}, \mathrm{L}$ and $\mathrm{S}$ was performed to assess the

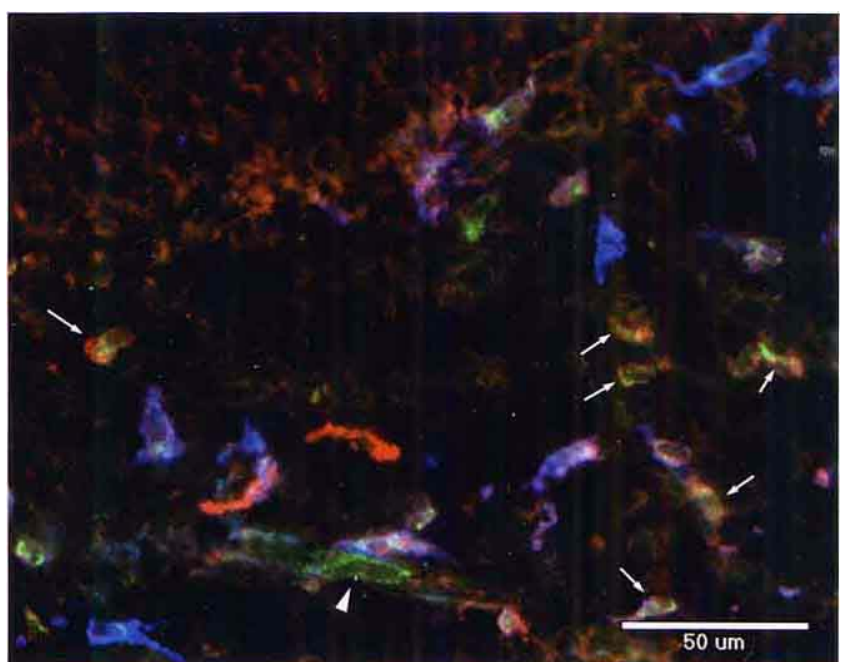

Fig. 5. Triple labeling of late pulp with anti-cystatin C (green), ED2 (red) and OX6 (blue). OX6 ${ }^{+}$cells and ED2 ${ }^{+}$cells (arrows) are abundant. An arrowhead shows an anti-cystatin $\mathrm{C}$ single positive cell. Bar $=50 \mu \mathrm{m}$.

proteolytic environment in the incisor pulp (Fig. 6A-C). Anti-cathepsin S, but not L or B, antibody labeled early and middle pulp (Fig. 6A-C). Double labeling with cystatin $\mathrm{C}$ and cathepsin $\mathrm{S}$ revealed that they were co-localized (Fig. 6D-F).

\section{Discussion}

In this study, oval-shaped anti-cystatin C positive cells were observed in the early and middle pulp, and, to a lesser degree, in the late pulp. Conventional electron microscopy revealed small juvenile macrophages in the early pulp. It is thus proposed that these cystatin C-positive cells are ED2macrophages. It is likely that these macrophages newly invaded dental pulp from blood vessels, supposedly formed de novo in the apical dental pulp. The cystatin C-positive macrophages in the rat incisor early pulp may be equivalent to ED1 single positive cells in rat molar pulp, since the $\mathrm{ED}^{+}{ }^{+} \mathrm{OX}^{-} \mathrm{ED}^{-}$cells were reported to be $2.9-3.8 \%$ of total $\mathrm{ED} 1^{+}$cells in adult rats and few ED1 ${ }^{+}$cells were present in the newborn rat molar pulp $[17,18]$.

Throughout the pulp, the majority of macrophages and dendritic cells stained positive with anti-cystatin $\mathrm{C}$ antibodies. Cystatin $\mathrm{C}$ is a normal blood plasma constituent. It is secreted constitutively by monocytes/macrophages, although cystatin $\mathrm{C}$ is ubiquitously expressed $[1,25]$. It is an endogenous cysteine protease inhibitor, and may function in regulating cysteine protease in the dental pulp. Indeed, in the current study, cathepsin $\mathrm{S}$ reactivity was detected in the rat incisor pulp. In dental pulp cells, cathepsin $\mathrm{S}$ was colocalized with cystatin $\mathrm{C}$, providing strong support that these cells were macrophages. Although the primary target for cathepsins are cellular lysosomes, a fraction of these enzymes are believed to be secreted into the extracellular space 

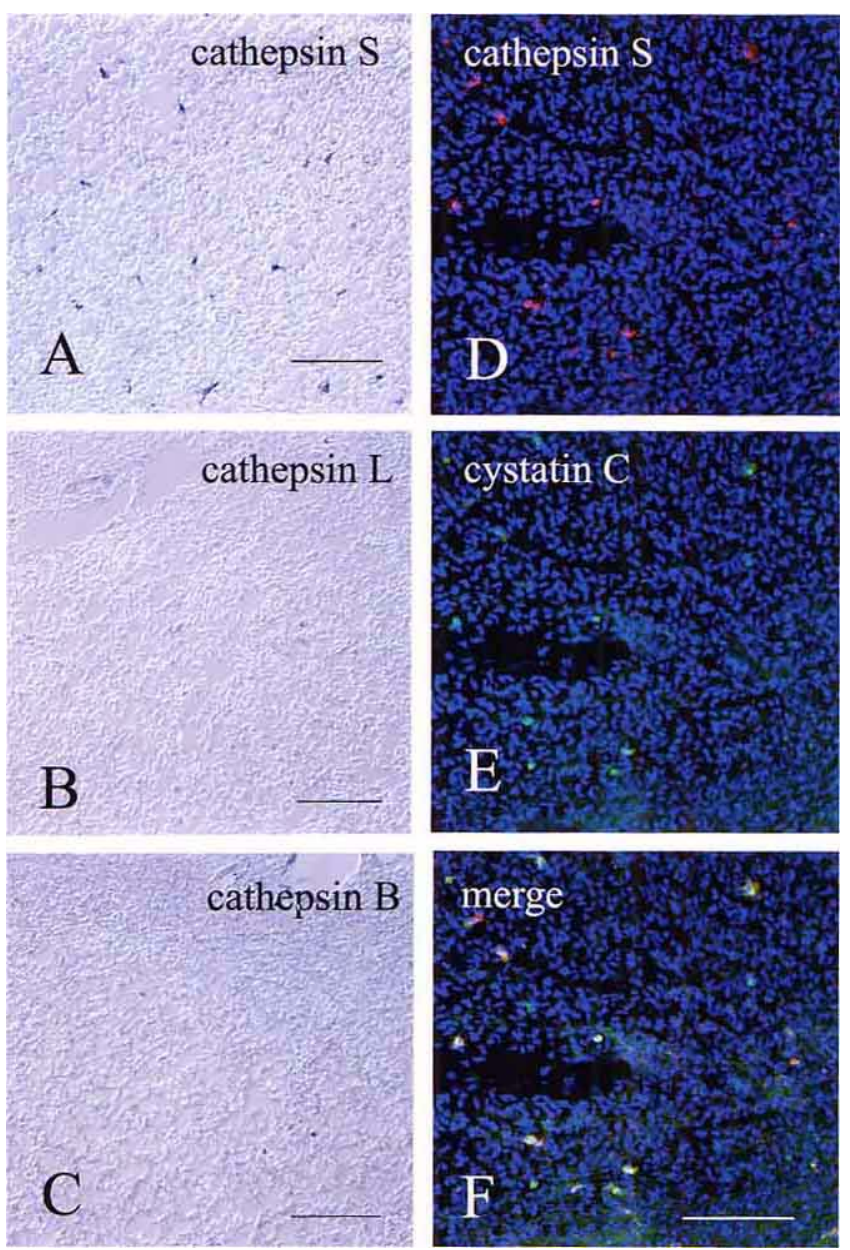

Fig. 6. (A-C) Immunolocalization of cathepsin $\mathrm{S}(\mathbf{A})$, cathepsin $\mathrm{L}$ (B) and cathepsin B (C) in early pulp. Cathepsin S (A) reactivity is evident, whereas cathepsin L (B) and B (C) reactivities are not seen. (D-F) Triple-labeling of early pulp with cathepsin S (red in D), anticystatin C (green in E), Hoechst 33342 (blue in D, E). An overlaid image is shown in F). Anti-cathepsin S antibodies are co-localized with anti-cystatin $\mathrm{C}$ antibodies $(\mathbf{F})$. Bars $=50 \mu \mathrm{m}$.

[3]. Proteolytic regulation by cathepsins and cystatin $\mathrm{C}$ has been widely reported in embryo plantation [2], normal organogenesis [20, 24, 27], and some pathological processes [21, 22 ]. Cystatin $\mathrm{C}$ is also reported to play a role in the proliferation of neural stem cells as a cofactor of FGF2 [23]. Cysteine proteases and their inhibitor, cystatin $\mathrm{C}$, may play a role in the normal pulp formation, although further study is needed.

In enamel organ epithelia of the rat incisors, cystatin $\mathrm{C}^{+}$ cells are few in the secretion zone but increase in maturation zone, which is a later stage of amelogenesis [15]. Therefore, three different pulp regions, that is, early, middle and late pulp, were examined in this study. In the current study, approximately half of the $\mathrm{OX} 6^{+}$cells in the middle and late pulp were $\mathrm{ED}^{+}$macrophages. The remaining $\mathrm{OX}^{+}$ cells may include dendritic cells $[14,16]$. In the molar pulp, numbers of $\mathrm{OX}^{+} \mathrm{ED} 2^{+}$macrophages are reported to be
$10-50 \%$ of $\mathrm{OX} 6^{+} \mathrm{ED} 2^{-}$cells [17]. More $\mathrm{OX} 6^{+}$macrophages were present in the incisor pulp in this study, but the reason for this is unclear. $\mathrm{OX}^{+}$macrophages and dendritic cells may play roles in immunological defense [9], clearance of apoptotic fragments, and possible immunotolerance [14].

In conclusion, based on their expression of cystatin $\mathrm{C}$ and cathepsin $\mathrm{S}$, these cells appear to be macrophages and putative dendritic cell populations, functioning to create a proteolytic environment in the pulp as well as in immunological defense and/or immunotolerance.

\section{Acknowledgments}

This work was supported in part by a grant from the Ministry of Education, Culture, Sports, Science and Technology of Japan to promote multidisciplinary Research Projects in 2001-2005.

\section{References}

1. Abrahamson, M., Olafsson, I., Palsdottir, A., Ulvsbäck, M., Lundwall, Å., Jensson, O. and Grubb, A. (1990) Structure and expression of the human cystatin C gene. Biochem. J. 268; 287294.

2. Afonso, S., Romagnano, L. and Babiarz, B. (1997) The expression and function of cystatin C and cathepsin B and cathepsin $\mathrm{L}$ during mouse embryo implantation and placentation. Development $124 ; 3415-3425$.

3. Chapman, H. A. (1991) Role of enzyme receptors and inhibitors in regulating proteolytic activities of macrophages. Ann. N.Y. Acad. Sci. 624; 87-96.

4. Damoiseaux, J. G. M. C., Döpp, E. A., Calame, W., Chao, D., MacPherson, G. G. and Dijkstra, C. D. (1994) Rat macrophage lysosomal membrane antigen recognized by monoclonal antibody ED1. Immunology 83; 140-147.

5. Dijkstra, C. D., Döpp, E. A., Joling, P. and Kraal, G. (1985) The heterogeneity of mononuclear phagocytes in lymphoid organs: distinct macrophage subpopulations in the rat recognized by monoclonal antibodies ED1, ED2 and ED3. Immunology 54; 589-599.

6. El-Sukkari, D., Wilson, N. S., Hakansson, K., Steptoe, R. J., Grubb, A., Shortman, K. and Villadangos, J. A. (2003) The protease inhibitor cystatin $\mathrm{C}$ is differentially expressed among dendritic cell population, but does not control antigen presentation. J. Immunol. 171; 5003-5011.

7. Friedrichs, B., Tepel, C., Reinheckel, T., Deussing, J., von Figura, K., Herzog, V., Peters, C., Saftig, P. and Brix, K. (2003) Thyroid functions of mouse cathepsins B, K, and L. J. Clin. Invest. 111; 1733-1745.

8. Garant, P. R. (1978) Microanatomy of the oral mineralized tissues. In "Textbook of Oral Biology", ed. by J. H. Shaw, E. A. Sweeney, C. C. Cappuccino and S. M. Meller, W. B. Saunders, Philadelphia, pp. 181-225.

9. Jontell, M. and Bergenholtz, G. (1992) Accesory cells in the immune defense of the dental pulp. Proc. Finn. Dent. Soc. 88 (Suppl. 1); 344-355.

10. Kaneko, T., Okiji, T., Kan, L., Suda, H. and Takagi, M. (2001) An immunoelectron-microscopic study of class II major histocompatibility complex molecule-expressing macrophages and dendritic cells in experimental rat periapical lesions. Arch. Oral Biol. 46; 713-720.

11. McMaster, W. R. and Williams, A. F. (1979) Identification of Ig glycoproteins in rat thymus and purification from rat spleen. Eur. 
J. Immunol. 9; 426-433.

12. Nishikawa, S. (2003) Immunohistochemical localization of SERCA2 in the ameloblasts of rat incisor. Acta Histochem Cytochem. 36; 331-334.

13. Nishikawa, S. and Sasaki, F. (1995) DNA localization in nuclear fragments of apoptotic ameloblasts using anti-DNA immunoelectron microscopy: programmed cell death of ameloblasts. Histochem. Cell Biol. 104; 151-159.

14. Nishikawa, S. and Sasaki, F. (1999) Apoptosis of dental pulp cells and their elimination by macrophages and MHC class IIexpressing dendritic cells. J. Histochem. Cytochem. 47; 303-311.

15. Nishikawa, S. and Sasaki, F. (2000) Detection of immature dendritic cells in the enamel organ of rat incisors by using anti-cystatin C and anti-MHC class II immunocytochemistry. J. Histochem. Cytochem. 48; 1243-1255.

16. Ohshima, H., Kawahara, I., Maeda, T. and Takano, Y. (1994) The relationship between odontoblasts and immunocompetent cells during dentinogenesis in rat incisors: an immunohistochemical study using OX6-monoclonal antibody. Arch. Histol. Cytol. 57; 435-447.

17. Okiji, T., Kawashima, N., Kosaka, T., Matsumoto, A., Kobayashi, C. and Suda, H. (1992) An immunohistochemical study of the distribution of immunocompetent cells, especially macrophages and Ia antigen-expressing cells of heterogeneous populations, in normal rat molar pulp. J. Dent. Res. 71; 11961202

18. Okiji, T., Kosaka, T., Kamal, A. M. M., Kawashima, N. and Suda, H. (1996) Age-related changes in the immunoreactivity of the monocyte/macrophage system in rat molar pulp. Arch. Oral Biol. 41; 453-460.

19. Pierre, P. and Mellman, I. (1998) Developmental regulation of invariant chain proteolysis controls MHC class II trafficking in mouse dendritic cells. Cell 93; 1135-1145.

20. Roth, W., Deussing, J., Botchkarev, V. A., Pauly-Evers, M.,
Saftig, P., Hafner, A., Schmidt, P., Schmahl, W., Scherer, J., Anton-Lamprecht, I., von Figura, K., Paus, R. and Peters, C. (2000) Cathepsin L deficiency as molecular defect of furless: hyperproliferation of keratinocytes and perturbation of hair follicle cycling. FASEB J. 14; 2075-2086.

21. Shi, G.-P., Sukhova, G. K., Grubb, A., Ducharme, A., Rhode, L. H., Lee, R. T., Ridker, P. M., Libby, P. and Chapman, H. A. (1999) Cystatin C deficiency in human atherosclerosis and aortic aneurysms. J. Clin. Invest. 104; 1191-1197.

22. Stypmann, J., Gläser, K., Roth, W., Tobin, D. J., Petermann, I., Matthias, R., Mönning, G., Haverkamp, W., Breithardt, G., Schmahl, W. and Peters, C. (2002) Dilated cardiomyopathy in mice deficient for the lysosomal cysteine peptidase cathepsin L. Proc. Natl. Acad. Sci. U S A 99; 6234-6239.

23. Taupin, P., Ray, J., Fischer, W. H., Suhr, S. T., Hakansson, K., Grubb, A. and Gage, F. H. (2000) FGF-2-responsive neural stem cell proliferation requires $\mathrm{CCg}$, a novel autocrine/paracrine cofactor. Neuron 28; 385-397.

24. Tobin, D. J., Foitzik, K., Reinheckel, T., Mecklenburg, L., Botchkarev, V. A., Peters, C. and Paus, R. (2002) The lysosomal protease cathepsin $\mathrm{L}$ is an important regulator of keratinocyte and melanocyte differentiation during hair follicle morphogenesis and cycling. Am. J. Pathol. 160; 1807-1821.

25. Warfel, A. H., Zucker-Franklin, D., Frangione, B. and Ghiso, J. (1987) Constitutive secretion of cystatin C ( $\gamma$-trace) by monocytes and macrophages and its downregulation after stimulation. J. Exp. Med. 166; 1912-1917.

26. Warshawsky, H. (1988) The teeth. In "Cell and Tissue Biology, a Textbook of Histology", 6th ed., ed. by L. Weiss, Urban \& Schwarzenberg, Baltimore, pp. 595-640.

27. Wright, W. W., Smith, L., Kerr, C. and Charron, M. (2003) Mice that express enzymatically inactive cathepsin L exhibit abnormal spermatogenesis. Biol. Reprod. 68; 680-687. 